\title{
Quantitative evaluation of dental bio-aerosols using particle count values. Part 1: the effect of High Volume Aspiration and natural ventilation.
}

Andre Haigh ( $\sim$ themicrodentist@gmail.com )

General Dental Practitioner, The Clearly Different Dental Practice, Derby

Ronuk Vasant ( $\square$ ronuk_vasant@hotmail.com )

Specialist in Prosthodontics, MK Vasant \& Associates, London

Dominic O'Hooley ( $\nabla$ dominicohooley@yahoo.co.uk)

Dentist, Adel Dental Practice, Leeds

\section{Research Article}

Keywords: dental aerosol, bio-aerosol, polydisperse aerosol, Light Scattering Airborne Particle Counter, Particle Count Values, fallow time

Posted Date: August 10th, 2020

DOI: https://doi.org/10.21203/rs.3.rs-55265/v1

License: (c) (i) This work is licensed under a Creative Commons Attribution 4.0 International License. Read Full License 


\section{Abstract}

Aim

Routine dental treatments are frequently associated with aerosol generating procedures (AGP). Recently dental AGP have attracted significant attention as a possible vector for the transmission of SARS-CoV-2 and attempts have been made to establish when a surgery may be safely decontaminated following a dental AGP - the 'fallow time'. There is a paucity of research in the dental literature regarding the near real time generation and dispersion of dental aerosol following a dental AGP. Study aims are to: (1) monitor dental aerosol generation and dispersal through semi-continuous particle count values (PCV), and (2) use this information to delineate a range of suitable fallow times.

\section{Method}

Following baseline measurements, five identical dental AGP were conducted on a dental manikin for each of three groups: (SEO) saliva ejector only, (HVA) high volume aspiration, (WO) high volume aspiration with windows open. For each procedure PCV were recorded every 2.2 minutes with a Light Scattering Airborne Particle Counter (LSAPC) for 3.3 hours. Eleven dependent variables were analysed, including baseline PCV, total PCV, peak PCV, time taken to return to one sample standard deviation of baseline PCV, and a time series extending from 15 minutes to 3 hours after cessation of AGP. Due to heterogeneity, the data was analysed with Krushkall-Wallis test and Dunn-Bonferroni post hoc.

\section{Results}

Between group mean baseline PCV were not statistically significant. Compared with SEO, WO had a statistically significant impact on peak PCV ( $p=.009)$ and HVA had a statistically significant impact on total PCV $(p=.006)$. With the exception at 2 and 3 hours, PCV throughout the time series were statistically significantly lower for WO and HVA in comparison with SEO. WO PCV were influenced by outdoor aerosol levels.

Four of the five SEO procedures failed to return to baseline PCV within 3.3 hours. Following AGP, the mean time for the HVA procedures to return to baseline PCV was 17.12 minutes, $95 \% \mathrm{Cl}[4.96$ to 29.28 ]. The effect of HVA on the time taken to return to baseline PCV was very large (Glass's $\Delta=-4.943, \mathrm{CLES}=1.00)$.

\section{Conclusion}

There is a significant benefit in opening windows during AGP.

The effect of HVA on reducing fallow time is very large. Under the conditions of this study, PCV suggest that it might be safe to consider a fallow time of 29.28 minutes.

\section{Introduction}

Many dental procedures involve the generation of aerosols which can become contaminated with patient saliva. SARS-CoV-2 has increased awareness of dental bio-aerosol as a potential route for disease transmission during dental procedures. It is widely recognised that all water lines will contain biofilm.1 Microorganisms resident within the biofilm can detach and become incorporated within the aerosol. Therefore the terms, "dental bio-aerosol" will be used throughout this series of papers to describe the aerosol emitted from dental equipment; and "contaminated dental bio-aerosol" to describe aerosol that has picked up salivary contaminants. Descriptions relating to aerosols more generally will be ascribed the term "aerosol".

\section{Characteristics of Dental Bio-aerosol}

The diameter of discrete particles containing biological material within bio-aerosol is usually $0.3-100 \mu \mathrm{m}$, made up of droplets (>10 $\mu \mathrm{m})$, course particles $(2.5-$ $10 \mu \mathrm{m})$, fine particles $(0.1-2.5 \mu \mathrm{m})$ and ultrafine particles $(<0.1 \mu \mathrm{m}) .2$, 3 Models suggest that the smallest of these particles $(<10 \mu \mathrm{m})$, possess the greatest potential to penetrate more deeply into the respiratory tract.4 56

Fine and ultra-fine particles are less influenced by gravity, have lower settling velocities, persist over extended timeframes,7, 8 and recirculate differently to larger particles. 9 Gravitational settling may occur hours or even days after aerosol generation,10 potentially exposing dental care professionals (DCP) and subsequent patients to an infectious dental bio- aerosol.10, 11, 12, 13, 14 Bio-aerosols have been identified as routes for transmission for Influenza A and varicella.6, 15 Most recently SARS-CoV-2 has been shown to remain viable in bio-aerosol beyond three hours. 16 However to date there have been no studies examining viruses within dental bio-aerosol, and virus containing dental bio-aerosol remains an unknown risk to patients and DCPs.10

Expanding our understanding of contaminated dental bio-aerosol is central to evaluating the potential consequences on human health and determining effective mitigation strategies. Contaminated dental bio-aerosol properties have been quantitatively and qualitatively evaluated,17, $18,19,20$ and dental bioaerosol distribution around the operating field has been appraised. 18, 21, 22, 23, 24, 25 However whilst these studies have provided invaluable insight into contaminated dental bio-aerosol, they have been unable to ascertain at what point the aerosol has been sufficiently dispersed to reduce the health risk to an acceptable level - the 'fallow time'.

'Fallow time' has been defined as that '...required for clearance of infectious aerosols after a particular [aerosol] procedure... before decontamination of the surgery can begin.'26 Fallow times of between 2 and 147 minutes have been suggested.26, 27, 28, 29 These times have been established through approximation of polydisperse aerosol properties, plotting dental splatter, non-continuous microbiological sampling, and observation of dental aerosol sedimentation using fluorescent tracers. 


\section{Polydisperse Aerosol}

Dental bio-aerosol, whether contaminated or not, is polydisperse. Monodisperse aerosols contain particles which have a geometric standard deviation less than 1.22.30 Where aerosols contain particles of differing sizes, they are termed polydisperse; the modelling of which is vastly more complicated than for monodisperse aerosol due to changes in polydisperse aerosol composition over time.7, 31 In a polydisperse aerosol it is estimated that approximately $40 \%$ of the mass is respirable. 5

When assessing an instrument capable of monitoring change in dental bio-aerosol, there are a number of elements to consider. It is impossible to distinguish all of the particles present in a polydisperse aerosol using a single technique.32 The aerosol properties can only be surmised from a measurement of a defined subset.31 Desirably a subset which contains particles that pose the greatest health hazard. 5 The instrument must be sufficiently flexible to detect fluctuations over short time periods, appropriately sensitive to these changes and sufficiently portable that it can be located in a dental surgery.

Whilst the use of cascade impactor samplers, cyclones and filters, provide quantitative and qualitative analysis of polydisperse aerosol, due to lengthy collection and turnaround times do not allow for semi-continuous or near real-time quantitative evaluation.33 3435 Consequently they have not conclusively resolved fallow time.

Away from dentistry there is a paucity of studies that have quantified the near real-time generation and dispersion of polydisperse aerosols.36 Currently no studies have examined the generation and dispersion of dental bio-aerosol inside a dental surgery in a near real-time semi-continuous manner.

\section{Measuring polydisperse aerosol Particle Count Values.}

The most commonly used types of particle concentration are number, mass, surface area, and volume concentration. Particle number concentrations are considered to more closely reflect the health exposure risk rather than particle mass and are used to characterize cleanrooms. 37

A number of real-time non-invasive in situ aerosol measurement techniques are available, the most practical of which are light scattering airborne particle counters (LSAPC). LSAPCs employ well-defined high intensity laser light to evaluate particle numbers and size in the sampling volume by analysing their light scattering behaviour. The scattered light is focused on to a photodetector where they generate an electrical signal. LSAPCs evaluate the probable particle size by matching the signal to that of spherical particles of known refractive index and size. LSAPCs offer continuous or semi-continuous near real-time data and benefit from only minimally disturbing the aerosol. They are however unable to provide a qualitative analysis of the composition of the aerosol and typically cannot distinguish particles whose diameter is less than $0.1 \mu \mathrm{m}$ from background noise. LSAPCs have been used to examine the relationship between air cleanliness in clinical environments, movement of personnel and infection rates.38, 39

There are other recognised limitations with LSAPCs.40 While large particles are distinguishable across the entire section of the laser, smaller particles may only be identified when they pass through the central beam. Large particles may also be erroneously identified as two smaller particles; or two small particles mistaken as a single larger particle. ISO 21501-4 details the calibration and verification for LSAPCs.37 It demands that LSAPCs meet a minimum standard including counting efficiency, sizing resolution, false count rate, concentration limit, sampling flow rate, sampling time and sampling volume.

The principal objective of this study was to monitor dental aerosol generation and dispersal through semi-continuous particle count values (PCV) of coarse and fine aerosol particles. The secondary objective was to use this information to define a range of suitable fallow times for: (1) unmitigated dental aerosol generating procedures (AGP); (2) AGP in conjunction with dental high volume aspiration (HVA), and: (3) a combination of HVA together with improved ventilation by way of opening windows.

\section{Methods}

All procedures were conducted in a $3.45 \mathrm{~m}^{\prime} 3.96 \mathrm{~m}^{\prime} 2.37 \mathrm{~m}(\mathrm{~h})$ dental surgery (volume $\left.32.38 \mathrm{~m} 3\right)$. To avoid inadvertently recording dental splatter, the LSAPC was positioned at a height of $1.35 \mathrm{~m}$ and $0.5 \mathrm{~m}$ from the operating field. This height was used as a compromise between a seated and standing DCP, and in a horizontal position previously shown to have been heavily contaminated.21 (Figure 1)

Prior to commencing the procedure, a water bottle was filled with 1.5 litres of reverse osmosis water and $15 \mathrm{ml}$ of Alpron. The water bottle was pressurised, and the room left for 15 minutes during which time the LSAPC was internally calibrated using a zero filter. Following reattachment of the measuring funnel, three baseline readings were recorded prior to each run to establish a mean baseline PCV and sample standard deviation.

A dental manikin (Nissin, Kyoto, Japan) was positioned on the dental chair so that the incisal edges of the mandibular lower incisors were $0.80 \mathrm{~m}$ from the floor. A pre-prepared mandibular right molar full crown preparation was 'polished' for each procedure with a 12- bladed tungsten carbide bur (Komet H375RDF314-018) in a turbine handpiece (KaVo Gentleforce Lux 7000B) for fifteen minutes. Mean flow rate was $90 \mathrm{ml} / \mathrm{minute}(\mathrm{SD}=0.707, \mathrm{n}=5)$. In order to ensure that the direction of the aerosol did not influence readings, the following procedure was followed: 1.5 minutes of up-milling, 1.5 minutes of down-milling, 1.5 minutes of occlusal polishing with the bur directed towards the tongue, 1.5 minutes of occlusal polishing with the bur directed towards the cheek. Potential influences during changes in handpiece angulation were minimised by momentarily releasing pressure on the foot pedal sufficient to eliminate flow of coolant. The cycle was repeated for fifteen minutes giving a total of 4.5 minutes up-milling, 4.5 minutes down-milling and each of the occlusal polishes receiving three minutes.

Suction was delivered by a Durr VSA 300 S providing 316l/min. When employed, high volume aspiration (HVA) was controlled by the single researcher (AH) in order to minimise additive bio-aerosol. A previous study has shown that aerosol distribution to be affected by the presence of an assistant, 21 and in a clinical 
environment PCV larger than $1 \mu \mathrm{m}$ have been shown to be more commonly associated with people. 9 Where a saliva ejector was solely employed, this was passively and consistently located through an opening posteriorly in the throat of the dental manikin. Where the windows were left open during the procedure, the windows were opened one hour prior to commencement of each procedure. The two open windows had a combined surface area of $1.18 \mathrm{~m} 2$.

Following a 22 second pre-sample clearance (1.0384 litres), PCV in a further 1.0384 litres of air were recorded every 2.2 minutes using an LSAPC (PC220, Trotec $\mathrm{GmbH}$, Heinsberg, Germany) recently calibrated in accordance with ISO 21501-4. After each procedure all remaining water was evacuated from the dental manikin, the room vacated and the air semi- continuously sampled for a further 3.3 hours. After 3.3 hours the dental manikin, the dental chair and equipment was disinfected and allowed to air dry.

The dental procedures were divided into three groups: Saliva Ejector Only (SEO); High Volume Aspiration alone (HVA); and high volume aspiration with Window Open (WO). There were five procedures for each group making a total of 15 procedures.

Data was imported into Microsoft Excel and was subsequently analysed with SPSS (IBM SPSS Statistics for Windows, Version 26.0. Armonk, NY: IBM Corp). These included baseline particle count value (bPCV); peak particle count value (pPCV); total particle count value (tPCV); particle count values at 15.8 minutes after cessation of AGP (PCV15), 31.2 minutes following AGP (PCV30); 46.6 minutes (PCV45); 62 minutes (PCV60); 90.6 minutes (PCV90); 121.4 minutes (PCV120); 180.8 minutes after cessation of AGP (PCV180); together with the time taken for particle count values to return to within one sample standard deviation of the baseline (SDPCV).

\section{Results}

To attain a $1 \%$ certainty the minimum PCV must be 1,000 particles.32 The polydisperse aerosol generated in this study failed to achieve sufficient counts of coarse PCV to allow for a separate analysis of these particles. Therefore analysis was conducted on cumulative PCV for all particles greater than $0.3 \mu \mathrm{m}$ (fine and coarse PCV).

The results can be seen in Table 1 and the summary for each of the three groups in Table 2. Four of the five SEO procedures failed to return to within one sample standard deviation of baseline within 3.3 hours. SDPCV for each of these procedures was therefore recorded as 198.40 minutes.

Departure from normality was evaluated with Shapiro-Wilk test for each of the dependent variables: bPCV, pPCV, tPCV, SDPCV, PCV15, PCV30, PCV45, PCV60, PCV90, PCV120, and PCV180.

Homogeneity of variances was assessed with Levene's test. The significance level was set at $5 \%$ for both tests. All of the dependent variables showed significant departure from at least one of the assumptions. Comparisons between the three groups (HVA, SEO, WO) was therefore performed with KruskalWallis and post hoc analyses with Dunn's test with Bonferroni correction. The significance level was set at $5 \%$. The results of these tests can be viewed in Table 3.

A plot of mean PCV over time for HVA, SEO and WO can be seen in Figure 2. The distribution of mean PCV15, PCV30, PCV45, PCV60, PCV90, PCV120, and PCV180 for HVA displayed a linear trend whose explained variance was high (92.05\%) (Figure 3). For SEO the distribution of the PCV was exponential with an explained variance of $99.41 \%$ (Figure 4). For WO the line of best fit followed a quadratic distribution with an explained variance of $78.51 \%$ (Figure 5).

The dissimilar distribution for WO is probably explained by prevailing drifts in outdoor natural and man-made aerosol for each of the five WO procedures (Figure 6). Whilst opening the window had no statistically significant effect on bPCV, it affected the ability to calculate SDPCV for WO. Therefore an independent samples analysis of SDPCV for HVA and SEO was performed with a Mann-Whitney U test. The significance level was $5 \%$. In comparison with SEO, HVA had a statistically significant effect on reducing SDPCV, $U(10)=0.000(Z=-2.611 ; p=.009)$. Due to unequal variances the effect size of HVA was calculated using Glass's Delta and Common Language Effect Size (CLES).41 The latter is considered robust to violations of parametric assumptions and easily understood. ${ }^{42}$ For SDPCV, Glass's $\Delta=-4.943$ and CLES $=1.00$

\section{Discussion}

Previous researchers have utilised fluorescent tracer to evaluate splatter and dental bio- aerosol sedimentation.21, 22, 23 Veena et al used a simple technique of allowing droplets containing fluorescent dye to settle onto filter paper arranged radially at discrete distances around a manikin.22 Mock scaling with an ultrasonic scaler was carried out, and the filter paper was replaced at specific time points to establish the rate of sedimentation. Filter paper placed up to 4 feet away recorded fluorescent tracer during the procedure. However 30 minutes after cessation of AGP, dye was only recorded on filter paper placed 1 foot away from the manikin.

Bentley et al performed a similar study combining fluorescent tracer and separate qualitative and quantitative analyses of dental aerosol and splatter, it was found that dental aerosol persisted for at least 10 minutes. 18 Aerosolised oral bacteria have been recovered in other investigations over time ranges from 20 minutes to three hours. $20,43,44$

Allison et al used fluorescent tracer dye and replaceable filter paper to detect splatter and dental bio-aerosol. 19 Photographs of the filter paper were assessed using software image analysis with further spectroflurometric analysis. A close correlation was found between the two techniques. At $30-40$ minutes, image analysis was unable to detect any fluorescein contamination whereas spectroflurometric analysis showed $0.02 \%$ of the original level. At $60-70$ minutes, image analysis again failed to detect any contamination of the filter paper, whereas spectroflurometric analysis showed an increase to $0.1 \%$. 
Modelling would suggest that fine and ultrafine particles remain airborne for a number of hours if not longer. 7, 8 The results from these studies would indicate that relying on the contamination of filter paper beyond 30 minutes following cessation of AGP might be insufficiently sensitive, regardless of the counting method employed. Furthermore, one of the studies suggested an additional secondary sedimentation beyond sixty minutes. 19

Suitable and appropriate RPE does not need to afford absolute respiratory protection against infectious bio-aerosols, only reduce the respiratory challenge.45 In one study fluorescent dye was isolated behind a single ply facemask and within the nose of the operator and their assistant.23 The effect of HVA on dental bio-aerosol is equivocal. An in-vivo study using collection plates noted no statistically significant difference in bio-aerosol and spatter reduction between high volume aspiration and saliva ejector. 46 Allison et al demonstrated a peripheral $67-75 \%$ reduction in contamination with fluorescent tracer.21

The results of the current study indicate that when compared with a saliva ejector, HVA is able to significantly reduce the total volume of aerosol. This observation was independent of increasing ventilation by opening windows. Accordingly, it can be expected that the use of HVA will favourably reduce the contaminated dental bio-aerosol challenge on DCP respiratory protective equipment (RPE).

The effect of room size remains unquantified. The LSAPC was positioned where previous studies had shown the greatest contamination occurred through fluorescent tracer. 19 The current study used only a single LSAPC and therefore cannot exclude discreet levels of polydisperse aerosol rather than uniform dispersion. Assuming uniform distribution, room size should plausibly affect particle concentration. However this study showed that dispersion of dental bioaerosol was procedure dependent (see Figures $\mathbf{2}$ and $\mathbf{3}$ ). In fact some of the experiments demonstrated a secondary settling (Brandon Spike) approximately 2.2 hours after primary dispersion of the polydisperse aerosol. However this was not observed in the majority of procedures and it was not possible to exclude this as an experimental artefact. Additional LSAPC may provide an indication of aerosol stratification.

Where the measure was a reduction in PCV to within one sample standard deviation of baseline, in comparison with SEO, the time was significantly reduced for HVA. The effect (Glass's $\Delta=-4.943$ ) was very large. An effect size of 1.0 is considered to correspond to about one year of education at primary school.47

The effect of opening windows on SDPCV was less easy to establish. PCV fluctuated whilst the windows were open, making a return to within 1 standard deviation of baseline difficult to establish. Oscillation in PCV varied. Varieties of PCV trends were observed during each experimental condition (Figure 6). Opening the windows risks contaminating the air with unknown aerosol. In the largest published investigation of indoor bioaerosol levels, culturable fungal spore concentrations were significantly greater outdoors than indoors.48 Additionally the survival of MERS-CoV in aerosol has been shown to be correlated to ambient air temperature and relative humidity, with viability reduced in hot and dry air.49 Considering the inability in the current study to show that aerosol dispersion was significantly different from use of HVA alone, the recommendation of increasing circulation by opening windows requires further investigation for SARS-CoV-2, where the negative effect of opening windows may become more significant during winter months when SARS-CoV-2 inactivation by sunlight may have a lesser effect.50 Repeating the experiment with a second LSAPC outdoors would have provided a baseline reference point from which to measure the effect.

Opening the window did however demonstrate a significantly lower pPCV, whilst HVA did not. This surprising finding may be explained by the conservative nature of the Dunn's test with Bonferroni correction. The non-adjusted $p$ value for HVA was .020 . Following adjustment for repeat testing, the $p$ value was .059. Despite the inability of this study to determine the effect of opening windows on fallow time, it would appear prudent to increase natural ventilation by opening windows for the duration of active AGP. This would reduce DCP peak exposure to contaminated dental bio-aerosol.

The secondary objective for this study was to provide an indication of fallow time through semi-continuous monitoring of PCV in dental bio-aerosols. In this study mean SDPCV for HVA was 17.12 minutes, $95 \% \mathrm{Cl}$ [4.96 to 29.28]. This finding is generally in agreement with Alison et al who used fluorescent tracer dye and 'suction' to assess dental bio-aerosol sedimentation.19 In contrast, Veena et al only used a saliva ejector which broadly is the equivalent of SEO in the current study. In that study, tracer dye could no longer be detected after 60 minutes. In the current study four of the five SEO procedures failed to return to within one sample standard deviation of baseline within 198.40 minutes. It is unclear whether this departure is due to the dental equipment employed (dental air turbine versus ultrasonic scaler), or the increased sensitivity to detect dental bio-aerosol longevity through PCV.

There are a number of factors which may shorten or lengthen fallow time. Diminished suction could be reasonably projected to increase SDPCV. However equally valid would be reduced duration of AGP or coolant flow rate from the dental equipment. The mean flow rate in this study was $90 \mathrm{ml} / \mathrm{minute}$. This equates over fifteen minutes to $90 \%$ of a 1.5 litre water bottle. It would seem unlikely the majority of dental procedures would approach this level of consumption at a single appointment, and accordingly the volume of dental bio-aerosol generated would be proportionately smaller. Furthermore ISO standards regarding minimum flow rates are only applicable in Europe,51 and North American equipment may not have sufficient capacity to meet these minimum flow rates. 52

The relationship between bio-aerosol PCV and microbiological counts or infection risk is equivocal. Some studies have observed a positive correlation between microbiological counts and PCV38, 53 whilst other researchers have not.33, 54 The fraction of contaminated dental bio- aerosol containing SARSCoV-2 and the risk of that aerosol to DCP and patients still remains unknown. Bennet et al suggested that DCP would inhale between $0.014 \mu$ and $01.12 \mu$ l of aerosolised saliva in a 15-minute peak exposure period.43 This did not take into account the effect of personal protective equipment. Viable SARS-CoV-2 has been retrieved from saliva, 55 with $1 \mathrm{~mL}$ containing $10^{4}$ to 108 copies. $56 \mathrm{It}$ has been suggested that for SARS-CoV-1 around 360 viral copies are necessary to generate a single PFU.57 This would suggest a potential 15- minute peak exposure for DCP of between 0.00038 and 33 PFU. Whilst the minimum infective dose in humans remain unknown, in a primate model cytopathic effect has been observed with bio-aerosol containing as few as 2,000 SARS-CoV-2 PFU.58 However valid, the arrival of such a figure is through a sequence of assumptions. The number of SARS-CoV-2 virions required to form a PFU may be lower than that for SARS-CoV-1, and in the clinical setting the true risk of exposure to salivary contaminated dental bio-aerosol may be higher. Accordingly a precautionary estimate, based on the $95 \%$ confidence interval of the mean SDPCV in the current study would suggest a mean fallow period of 29.28 minutes under similar conditions. It is important to recognise that the population mean fallow time will always remain unknown.

Page 5/15 


\section{Conclusion}

There is no singular method for establishing fallow time. Qualitative analysis may demonstrate whether viable and non-viable virions are present, yet cannot establish when a dental bio-aerosol has dissipated. Studies using tracer dyes are capable of assessing the distribution of splatter and dental bio-aerosol, however by their very nature are unable to provide near real-time evaluation of aerosol sedimentation. Semi-continuous quantitative analysis such as the one conducted in this study allows for near real-time monitoring of aerosol generation and dispersal. This provides sufficient granularity to assess when PCV have been restored to one within sample standard deviation of baseline following a dental AGP. However, other than for size, LSAPC do not discriminate between particles. This was a significant problem in the design of the current study. Sufficient to prevent the complete appraisal of increased natural ventilation through opening windows.

Accordingly it accepted that reductions in PCV should not be directly translated into a view that 'the air or room is now safe.' However PCV are able to quantify the dispersal of fine and coarse particles within dental bio-aerosol, from the cessation of dental AGP without resorting to theoretical modelling. With the precautionary approach of PCV returning to within one sample standard deviation of baseline, and a $95 \%$ confidence level, this study would suggest a fallow period of 29.28 minutes should significantly reduce the exposure risk of DCP and patients to contaminated dental bio-aerosol. This finding strongly supports the conclusion of Allison et al, who using fluorescent tracer concluded that it may be safe to reduce fallow to 30 minutes.21

Despite the inability of this study to demonstrate the effect of increased natural ventilation on fallow time, opening windows reduced peak dental bio-aerosol levels during periods of active AGP.

The authors are currently conducting further studies to determine the effectiveness of a variety of mitigation strategies on dental bio-aerosol.

\section{Declarations}

\section{Competing interests:}

André Haigh declares no competing interests. Ronuk Vasant declares no competing interests. Dominic O'Hooley declares no competing interests.

\section{Funding:}

The authors received no external funding for this research.

\section{References}

1. Szymanska J, Sitkowska J, Dutkiewicz J. Microbial contamination of dental unit waterlines. Annals of agricultural and environmental medicine : AAEM 2008; 15(2): 173-9.

2. Size Distribution Characteristics Of In Kulkarni P, Baron PA, Willeke K (ed) Aerosol Measurement: Principles, Techniques, and Applications. pp 41-54. 2011.

3. Methods For Chemical Analysis Of Atmospheric Aerosols. In Kulkarni P, Baron PA, Willeke K (ed) Aerosol Measurement: Principles, Techniques, and Applications. pp 153-77. 2011.

4. Gralton J, Tovey E, McLaws ML, Rawlinson The role of particle size in aerosolised pathogen transmission: a review. The Journal of infection 2011; 62(1): 1-13.

5. Hinds WC. 11 Respiratory Deposition. (ed) Aerosol Technology: Properties, Behavior, and Measurement of Airborne Particles. pp 233-59. WileyInterscience,

6. Tellier Aerosol transmission of influenza A virus: a review of new studies. Journal of the Royal Society, Interface 2009; 6 Suppl 6: S783-90.

7. Lindauer GC, Castleman AW. Behavior of aerosols undergoing brownian coagulation and gravitational settling in closed systems. Journal of Aerosol Science 1971; 2(2): 85-91.

8. Hinds WC. 4 Uniform Particle Motion. (ed) Aerosol Technology: Properties, Behavior, and Measurement of Airborne Particles. pp 42-74. Wiley-Interscience,

9. Pankhurst LJ, Taylor J, Cloutman-Green EA, Hartley JC, Lai KM. Can Clean-Room Particle Counters be Used as an Infection Control Tool in Hospital Operating Theatres? Indoor and Built Environment 2011; 21(3): 381-91.

10. Zemouri C, de Soet H, Crielaard W, Laheij A. A scoping review on bio-aerosols in healthcare and the dental environment. PloS one 2017; 12(5):

11. Harrel SK, Molinari Aerosols and splatter in dentistry: a brief review of the literature and infection control implications. Journal of the American Dental Association 2004; 135(4): 429-37.

12. Office of the Chief Dental Officer (England). Standard operating procedure: Transition to recovery (version 2). NHS England and NHS Improvement 17 June

13. Resuming General Dental Services Following COVID-19 Shutdown: A guide and implementation tools for general dental practice. For Phases 2 and 3 of dental services remobilisation (Version 1.1). Scottish Dental Clinical Effectiveness Programme 12 June 2020.

14. Supplementary Document 1 - Assessing the evidence base for medical procedures which may create a higher risk of respiratory infection transmission from patient to healthcare worker (Version 1.0). NHS National Services Scotland 15 April

15. Gustafson TL, Lavely GB, Brawner ER, Jr., Hutcheson RH, Jr., Wright PF, Schaffner W. An outbreak of airborne nosocomial varicella. Pediatrics 1982; 70(4): 550-6. 
16. van Doremalen N, Bushmaker T, Morris DH, Holbrook MG, Gamble A, Williamson BN, et al. Aerosol and Surface Stability of SARS-CoV-2 as Compared with SARS-CoV-1. The New England journal of medicine 2020; 382(16): 1564-7.

17. Manarte-Monteiro $\mathrm{P}, \mathrm{Carvalho} \mathrm{A}$, Pina $\mathrm{C}$, Oliveira $\mathrm{H}$, Manso Air quality assessment during dental practice: Aerosols bacterial counts in an universitary clinic. Revista Portuguesa de Estomatologia, Medicina Dentária e Cirurgia Maxilofacial 2013; 54(1): 2-7.

18. Bentley CD, Burkhart NW, Crawford JJ. Evaluating spatter and aerosol contamination during dental procedures. Journal of the American Dental Association 1994; 125(5): 579-84.

19. Timmerman MF, Menso L, Steinfort J, van Winkelhoff AJ, van der Weijden GA. Atmospheric contamination during ultrasonic Journal of clinical periodontology 2004; 31(6): 458-62.

20. Grenier D. Quantitative analysis of bacterial aerosols in two different dental clinic environments. Applied and environmental microbiology 1995; 61(8): 3165-8.

21. Allison JR, Currie CC, Edwards DC, Bowes C, Coulter J, Pickering K, et al. Evaluating aerosol and splatter following dental procedures.

22. Veena HR, Mahantesha S, Joseph PA, Patil SR, Patil SH. Dissemination of aerosol and splatter during ultrasonic scaling: a pilot study. Journal of infection and public health 2015; 8(3): 260-5.

23. Dahlke WO, Cottam MR, Herring MC, Leavitt JM, Ditmyer MM, Walker RS. Evaluation of the spatter-reduction effectiveness of two dry-field isolation techniques. Journal of the American Dental Association 2012; 143(11): 1199-204.

24. Rivera-Hidalgo F, Barnes JB, Harrel SK. Aerosol and splatter production by focused spray and standard ultrasonic inserts. Journal of periodontology 1999 ; 70(5): 473-7.

25. Harrel SK, Barnes JB, Rivera-Hidalgo F. Aerosol and splatter contamination from the operative site during ultrasonic scaling. Journal of the American Dental Association 1998; 129(9): 1241-9.

26. Implications of COVID-19 for the safe management of general dental practice: A practical College of General Dentistry and Faculty of General Dental Practice (UK) 1 June 2020.

27. Aerosol Generating Procedures and their Mitigation in International Dental Guidance Documents - A Rapid Review. COVID-19 Dental Services Evidence Review (CoDER) Working Group 24 July 2020

28. Wilson G, Dave M, Colloc T, Richards D. A comparison of UK return-to-practice guidance and standard operating procedure Scottish Dental Clinical Effectiveness Programme 19 June 2020.

29. SBAR Ventilation, water and environmental cleaning in dental surgeries relating to COVID-19 (v1.0). National Services Scotland. 17 July

30. Fromen CA, Shen TW, Larus AE, Mack P, Maynor BW, Luft JC, et al. Synthesis and characterization of monodisperse uniformly shaped respirable aerosols. AlChE Journal 2013; 59(9): 3184-94.

31. Physical And Chemical Processes In Aerosol Systems. In Kulkarni P, Baron PA, Willeke K (ed) Aerosol Measurement: Principles, Techniques, and Applications. pp 31-40.

32. An Approach To Performing Aerosol Measurements. In Kulkarni P, Baron PA, Willeke K (ed) Aerosol Measurement: Principles, Techniques, and Applications. pp 55-65.

33. Lednicky JA, Loeb Detection and Isolation of Airborne Influenza A H3N2 Virus Using a Sioutas Personal Cascade Impactor Sampler. Influenza research and treatment 2013; 2013: 656825.

34. Booth TF, Kournikakis B, Bastien N, Ho J, Kobasa D, Stadnyk L, et al. Detection of airborne severe acute respiratory syndrome (SARS) coronavirus and environmental contamination in SARS outbreak units. The Journal of infectious diseases 2005; 191(9): $1472-7$.

35. Dybwad M, Skogan G, Blatny Comparative Testing and Evaluation of Nine Different Air Samplers: End-to-End Sampling Efficiencies as Specific Performance Measurements for Bioaerosol Applications. Aerosol Science and Technology 2014; 48(3): 282-95.

36. Gold K, Cheng YS, Holmes TD. A quantitative analysis of aerosols inside an armored vehicle perforated by a kinetic energy penetrator containing tungsten, nickel, and cobalt. Military medicine 2007; 172(4): 393-8.

37. ISO 21501-4:2018. Determination of particle size distribution - Single particle light interaction methods - Part 4: Light scattering airborne particle counter for clean spaces. International Organization for Standardization, Geneva, Switzerland.

38. Birgand G, Toupet G, Rukly S, Antoniotti G, Deschamps MN, Lepelletier D, et al. Air contamination for predicting wound contamination in clean surgery: A large multicenter study. American journal of infection control 2015; 43(5): 516-21.

39. Teter J, Guajardo I, Al-Rammah T, Rosson G, Perl TM, Manahan M. Assessment of operating room airflow using air particle counts and direct observation of door openings. American journal of infection control 2017; 45(5): 477-82.

40. Hovenac EA. Performance and operating envelope of imaging and scattering particle sizing instruments. International Congress on Applications of Lasers \& Electro-Optics 1987: 174-81.

41. McGraw KO, Wong SP. A common language effect size statistic. Psychological Bulletin 1992; 111(2): 361-5.

42. Ruscio J. A probability-based measure of effect size: robustness to base rates and other factors. Psychological methods 2008; 13(1): 19-30.

43. Bennett AM, Fulford MR, Walker JT, Bradshaw DJ, Martin MV, Marsh PD. Microbial aerosols in general dental practice. British dental journal 2000; 189(12): 664-7.

44. Chuang C-Y, Cheng H-C, Yang S, Fang W, Hung P-C, Chuang S-Y. Investigation of the spreading characteristics of bacterial aerosol contamination during dental scaling treatment. Journal of Dental Sciences 2014; 9(3): 294-6.

45. Health and Safety Executive: Respiratory protective equipment at work: A practical guide. London: HMSO

Page $7 / 15$ 
46. Holloman JL, Mauriello SM, Pimenta L, Arnold RR. Comparison of suction device with saliva ejector for aerosol and spatter reduction during ultrasonic scaling. Journal of the American Dental Association 2015; 146(1): 27-33.

47. Coe Effect size. In Arthur J (ed) Research Methods and Methodologies in Education. pp 368-77. SAGE Publications Ltd, 2012.

48. Shelton BG, Kirkland KH, Flanders WD, Morris Profiles of airborne fungi in buildings and outdoor environments in the United States. Applied and environmental microbiology 2002; 68(4): 1743-53.

49. Pyankov OV, Bodnev SA, Pyankova OG, Agranovski IE. Survival of aerosolized coronavirus in the ambient air. J Aerosol Sci 2018; 115: 158-63.

50. Schuit M, Ratnesar-Shumate S, Yolitz J, Williams G, Weaver W, Green B, et Airborne SARS-CoV-2 Is Rapidly Inactivated by Simulated Sunlight. The Journal of infectious diseases 2020; 222(4): 564-71.

51. ISO 14457:2017. Dentistry - Handpieces and motors. International Organization for Standardization, Geneva, Switzerland.

52. Siegel SC, von Fraunhofer JA. Irrigation rates and handpieces used in prosthodontic and operative dentistry: results of a survey of North American dental school Journal of prosthodontics : official journal of the American College of Prosthodontists 2000; 9(2): 82- 6.

53. Armadans-Gil L, Rodriguez-Garrido V, Campins-Marti M, Gil-Cuesta J, Vaque-Rafart J. Particle counting and microbiological air sampling: results of the simultaneous use of both procedures in different types of hospital rooms. Enfermedades infecciosas y microbiologia clinica 2013; 31(4): 217-21.

54. Li C-S, Hou P-A. Bioaerosol characteristics in hospital clean Science of The Total Environment 2003; 305(1-3): 169-76.

55. To KK, Tsang OT, Chik-Yan Yip C, Chan KH, Wu TC, Chan JMC, et Consistent detection of 2019 novel coronavirus in saliva. Clinical infectious diseases : an official publication of the Infectious Diseases Society of America 2020.

56. Zhu J, Guo J, Xu Y, Chen X. Viral dynamics of SARS-CoV-2 in saliva from infected patients. The Journal of infection

57. Vicenzi E, Canducci F, Pinna D, Mancini N, Carletti S, Lazzarin A, et al. Coronaviridae and SARS-associated coronavirus strain HSR1. Emerging infectious diseases 2004; 10(3): 413-8.

58. Blair RV, Vaccari M, Doyle-Meyers LA, Roy CJ, Russell-Lodrigue K, Fahlberg M, et al. ARDS and Cytokine Storm in SARS-CoV-2 Infected Caribbean Vervets. 2020.

\section{Tables}

\section{Table 1: Particle Count Values}




\begin{tabular}{|c|c|c|c|c|c|c|c|c|c|c|c|}
\hline & $\begin{array}{l}\text { bPCV } \\
\text { (Sample SD, n=3) }\end{array}$ & & & & & & & & & & \\
\hline Description & & pPCV & $\mathrm{tPCV}$ & SDPCV & PCV15 & PCV30 & PCV45 & PCV60 & PCV90 & PCV120 & PCV180 \\
\hline \multirow[t]{2}{*}{ HVA } & $5,210.33$ & 9,726 & 474,805 & 29 & 6,416 & 5,546 & 3,990 & 3,199 & 1,941 & 4,318 & 4,674 \\
\hline & (626.03) & & & & & & & & & & \\
\hline \multirow[t]{2}{*}{ HVA } & $6,476.67$ & 14,929 & 480,002 & 4.80 & 6,280 & 6,239 & 5,642 & 5,488 & 4,586 & 4,545 & 2,667 \\
\hline & $(561.66)$ & & & & & & & & & & \\
\hline \multirow[t]{2}{*}{ HVA } & $7,139.33$ & 20,061 & 544,892 & 11.40 & 6,010 & 5,881 & 6,575 & 5,612 & 5,200 & 4,540 & 3,762 \\
\hline & $(850.50)$ & & & & & & & & & & \\
\hline \multirow[t]{2}{*}{ HVA } & $3,735.67$ & 4,760 & 352,184 & 24.60 & 4,749 & 3,951 & 3,608 & 3,421 & 3,024 & 3,864 & 3,241 \\
\hline & (257.09) & & & & & & & & & & \\
\hline \multirow[t]{2}{*}{ HVA } & $5,825.67$ & 11,143 & 499,899 & 15.80 & 6,325 & 5,669 & 5,807 & 6,751 & 6,339 & 5,546 & 5,069 \\
\hline & $(684.46)$ & & & & & & & & & & \\
\hline \multirow[t]{2}{*}{ SEO } & $4,408.67$ & 131,267 & $3,289,611$ & 123.20 & 74,514 & 43,971 & 32,380 & 20,893 & 15,745 & 26,505 & 12,867 \\
\hline & (891.92) & & & & & & & & & & \\
\hline \multirow[t]{2}{*}{ SEO } & $5,421.00$ & 167,332 & $3,119,053$ & 198.40 & 99,541 & 47,707 & 29,364 & 23,078 & 10,038 & 5,030 & 3,976 \\
\hline & $(2,230.02)$ & & & & & & & & & & \\
\hline \multirow[t]{2}{*}{ SEO } & $5,961.00$ & 147,806 & $4,917,563$ & 198.40 & 124,060 & 88,497 & 75,328 & 52,281 & 37,528 & 21,159 & 11,085 \\
\hline & $(584.25)$ & & & & & & & & & & \\
\hline \multirow[t]{2}{*}{ SEO } & $4,879.00$ & 220,560 & $5,590,313$ & 198.40 & 145,857 & 112,752 & 106,263 & 69,066 & 33,247 & 16,963 & 7,323 \\
\hline & (326.32) & & & & & & & & & & \\
\hline \multirow[t]{2}{*}{ SEO } & $6,527.33$ & 223,241 & $5,749,861$ & 198.40 & 140,729 & 89,994 & 70,940 & 5,8821 & 44,422 & 2,7504 & 16,935 \\
\hline & (755.78) & & & & & & & & & & \\
\hline \multirow[t]{2}{*}{ Wo } & $2,727.00$ & 5,458 & 237,494 & $-a$ & 1,427 & 1,950 & 1,208 & 1,821 & 2,361 & 2,238 & 2,572 \\
\hline & (838.13) & & & & & & & & & & \\
\hline \multirow[t]{2}{*}{ Wo } & $7,346.00$ & 11,653 & 985,997 & $-a$ & 7,518 & 8,107 & 7,464 & 7,264 & 9,616 & 11,315 & 14,327 \\
\hline & $(1,295.47)$ & & & & & & & & & & \\
\hline \multirow[t]{2}{*}{ WO } & $4,911.00$ & 7,675 & 565,498 & $-a$ & 4,780 & 5,044 & 5,195 & 5,770 & 4,845 & 5,609 & 6,893 \\
\hline & (52.83) & & & & & & & & & & \\
\hline \multirow[t]{2}{*}{ Wo } & $3,848.00$ & 4,379 & 508,093 & $-a$ & 4,023 & 3,402 & 3,667 & 3,535 & 5,214 & 6,682 & 7,746 \\
\hline & (394.97) & & & & & & & & & & \\
\hline \multirow[t]{2}{*}{ Wo } & $12,365.00$ & 12,748 & 631,182 & $-a$ & 9,050 & 10,436 & 9,333 & 7,443 & 4,608 & 3,472 & 2,914 \\
\hline & $(520.77)$ & & & & & & & & & & \\
\hline
\end{tabular}

aunable to calculate SDPCV for WO. See results section for further details

Table 2: Group means 


\begin{tabular}{|c|c|c|c|c|c|c|c|c|c|c|c|}
\hline \multirow[t]{2}{*}{ Group } & & bPCV & pPCV & tPCV & SDPCV & PCV15 & PCV30 & PCV45 & PCV60 & PCV90 & PCV12 \\
\hline & Mean & $5,612.79$ & $12,123.80$ & $470,356.53$ & 17.12 & $5,956.00$ & $5,457.20$ & $5,124.40$ & $4,894.20$ & $4,218.00$ & 4,562 . \\
\hline \multirow[t]{3}{*}{ HVA } & $\begin{array}{l}\text { Std. } \\
\text { Deviation }\end{array}$ & $1,216.955$ & $5,740.323$ & $71,599.413$ & 9.789 & 691.466 & 882.072 & $1,267.322$ & $1,529.670$ & $1,747.051$ & 615.58 \\
\hline & $(n=5)$ & & & & & & & & & & \\
\hline & Mean & $5,439.40$ & $178,041.20$ & $4,533,280.29$ & 183.36 & $116,940.30$ & $76,584.32$ & $62,855.10$ & $44,827.91$ & $28,196.09$ & 19,432 \\
\hline \multirow[t]{3}{*}{ SEO } & $\begin{array}{l}\text { Std. } \\
\text { Deviation }\end{array}$ & 841.496 & $42,034.362$ & $1,254,174.352$ & 33.630 & $29,814.087$ & $29,695.862$ & $32,231.887$ & $21,707.105$ & $14,668.300$ & 9,106 \\
\hline & $(n=5)$ & & & & & & & & & & \\
\hline & Mean & $6,239.40$ & $8,382.60$ & $585,652.80$ & $-a$ & $5,359.60$ & $5,787.80$ & $5,373.40$ & $5,166.60$ & 5328.80 & 5,863 \\
\hline \multirow[t]{2}{*}{ WO } & $\begin{array}{l}\text { Std. } \\
\text { Deviation }\end{array}$ & $3,826.484$ & $3,702.534$ & $269,251.126$ & $-a$ & $2,994.391$ & $3,462.602$ & $3,175.816$ & $2,439.279$ & $2,643.611$ & 3,511 . \\
\hline & $(n=5)$ & & & & & & & & & & \\
\hline
\end{tabular}

aunable to calculate mean SDPCV for WO. See results section for further details

Table 3: Results of Krushkall-Wallis test with Dunn's post hoc analysis

\begin{tabular}{|c|c|c|c|c|c|c|}
\hline \multicolumn{4}{|c|}{ Kruskall-Wallis } & \multicolumn{3}{|c|}{ Adjusted significance ${ }^{a}$} \\
\hline & $H$-value & d.f. & $p$ value & WO-HVA & WO-SEO & HVA-SEO \\
\hline bPCV & 0.060 & 2 & .970 & - & - & - \\
\hline pPCV & 9.780 & 2 & $.008^{\star \star}$ & 1.000 & $.009^{\star \star}$ & .059 \\
\hline tPCV & 10.220 & 2 & $.006^{* *}$ & 1.000 & .085 & $.006^{\star *}$ \\
\hline SDPCV & 7.258 & 1 & $.007^{\star *}$ & $-b$ & $-b$ & $-b$ \\
\hline PCV15 & 9.420 & 2 & $.009^{* *}$ & 1.000 & $.017^{\star}$ & $.033^{*}$ \\
\hline PCV30 & 9.420 & 2 & $.009^{* *}$ & 1.000 & $.017^{\star}$ & $.033^{*}$ \\
\hline $\mathrm{PCV}^{45}$ & 9.380 & 2 & $.009^{\star *}$ & 1.000 & $.027^{\star}$ & $.022^{*}$ \\
\hline PCV60 & 9.620 & 2 & $.008^{\star *}$ & 1.000 & $.049^{*}$ & $.011^{*}$ \\
\hline PCV90 & 9.620 & 2 & $.008^{\star *}$ & 1.000 & $.049^{\star}$ & $.011^{*}$ \\
\hline PCV120 & 6.860 & 2 & $.032^{*}$ & 1.000 & .143 & $.040^{*}$ \\
\hline PCV180 & 4.560 & 2 & .102 & - & - & - \\
\hline
\end{tabular}

*significant at 0.05 level

**significant at 0.01 level

aDunn's post hoc with Bonferroni adjustment

bunable to calculate SDPCV for WO. See Mann-Whitney U test in results section for SEO-HVA

\section{Figures}




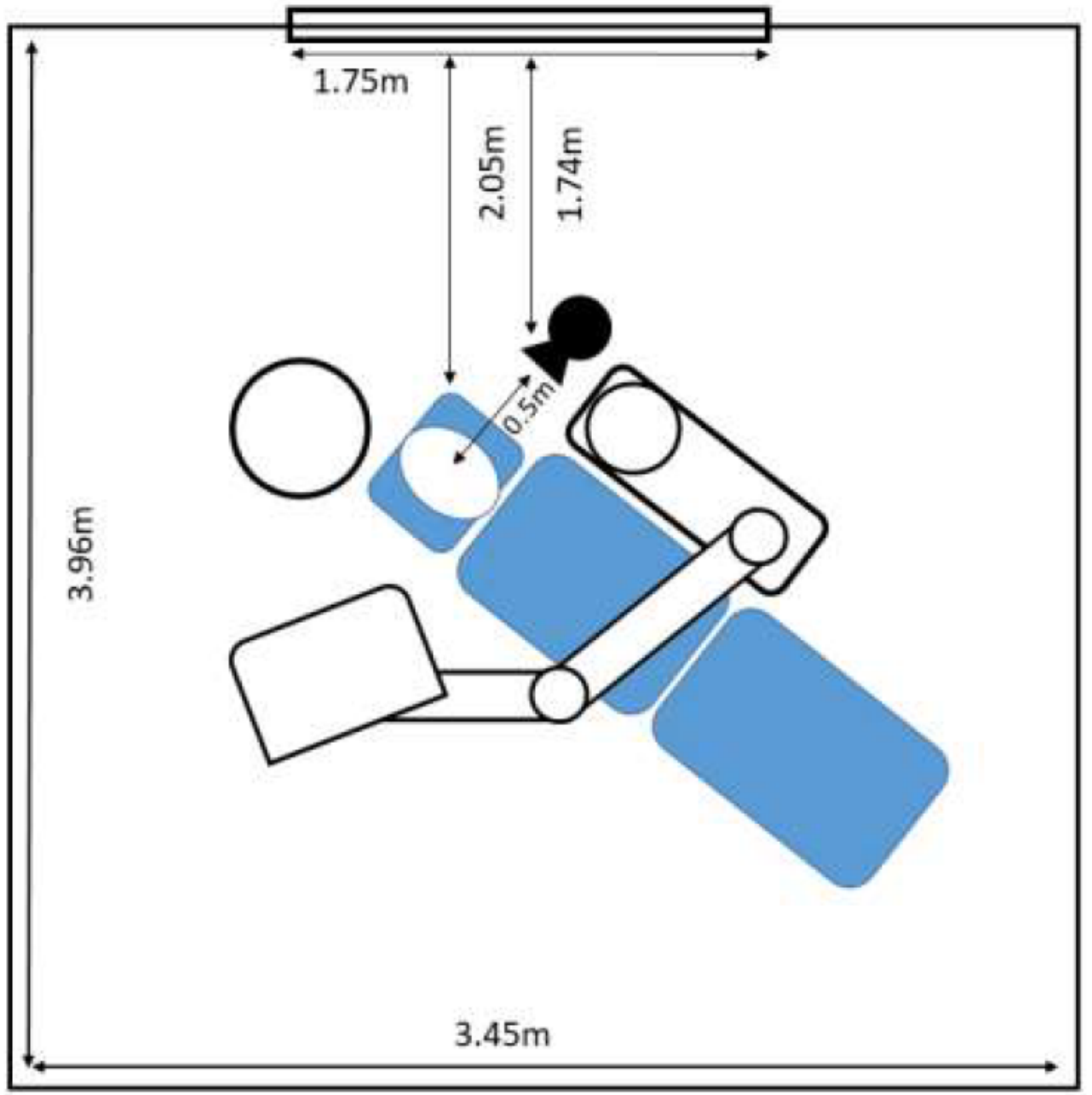

Figure 1

Dimensions of surgery and location of LSAPC 


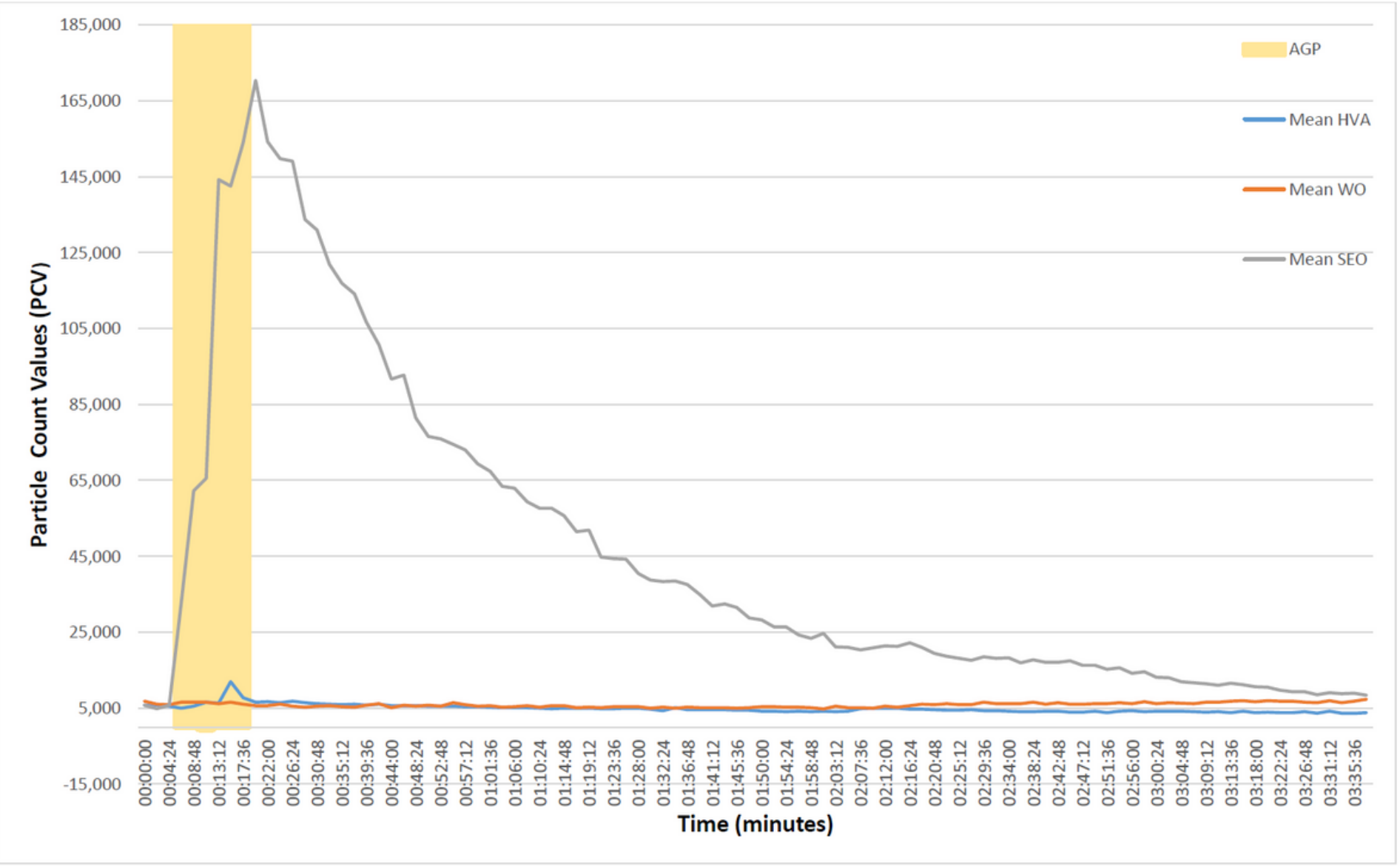

Figure 2

Particle Count Values (PCV) over time

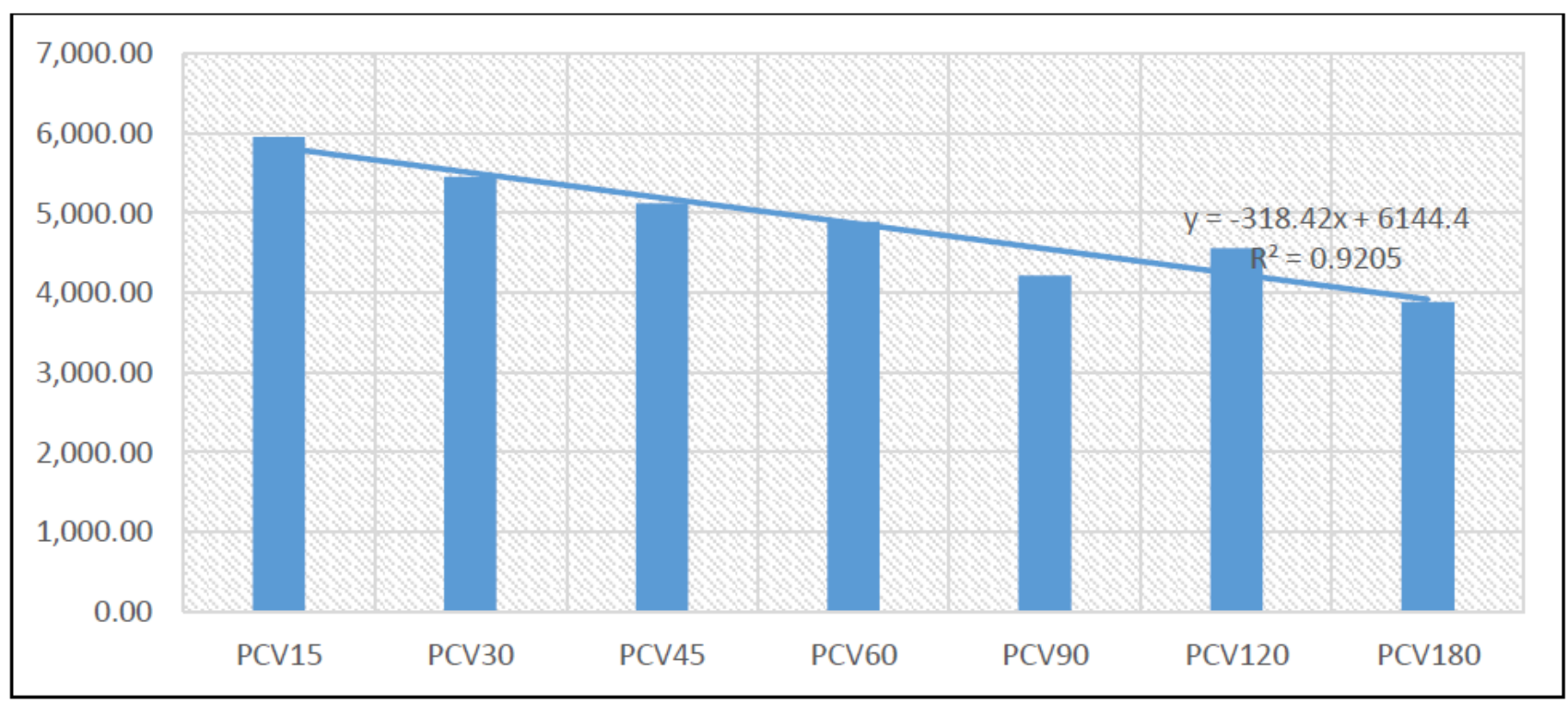

\section{Figure 3}

Distribution of PCV for HVA 


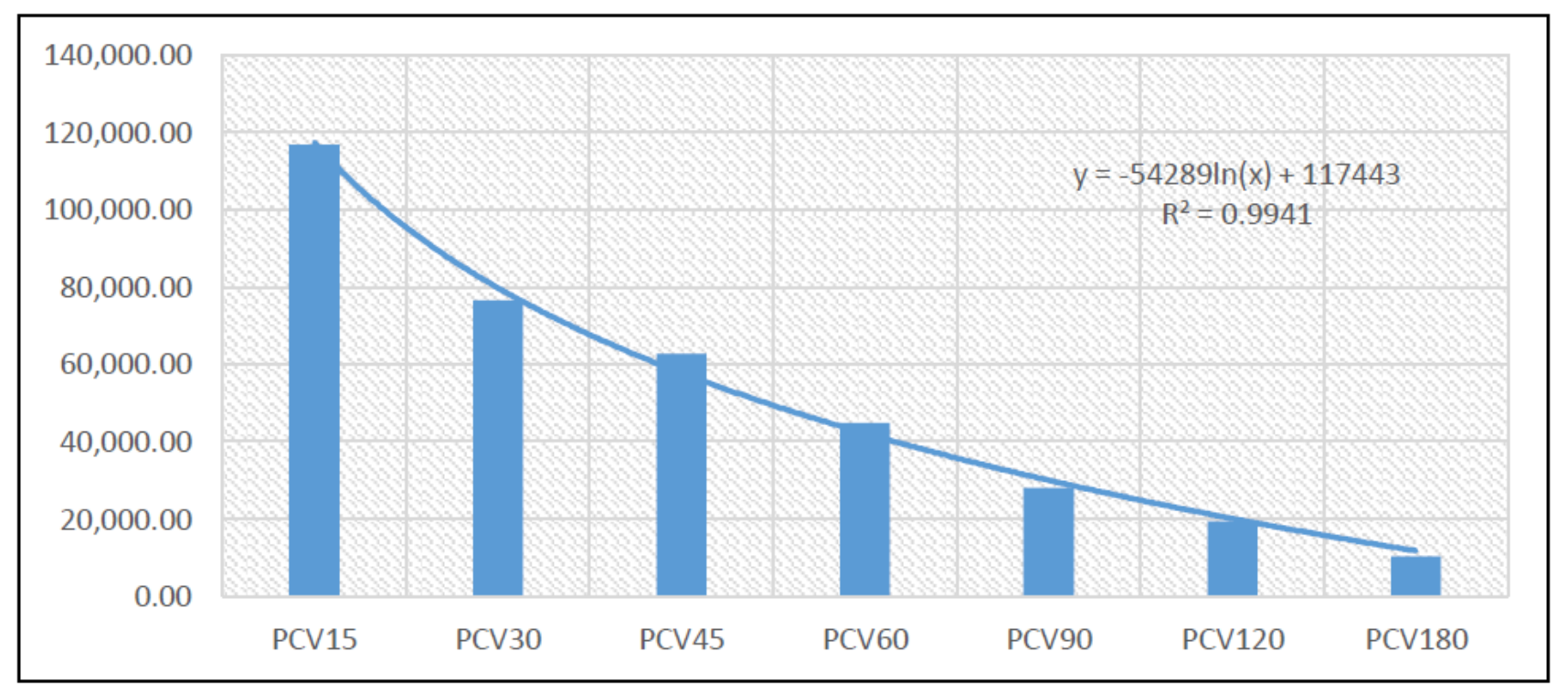

Figure 4

Distribution of PCV for SEO

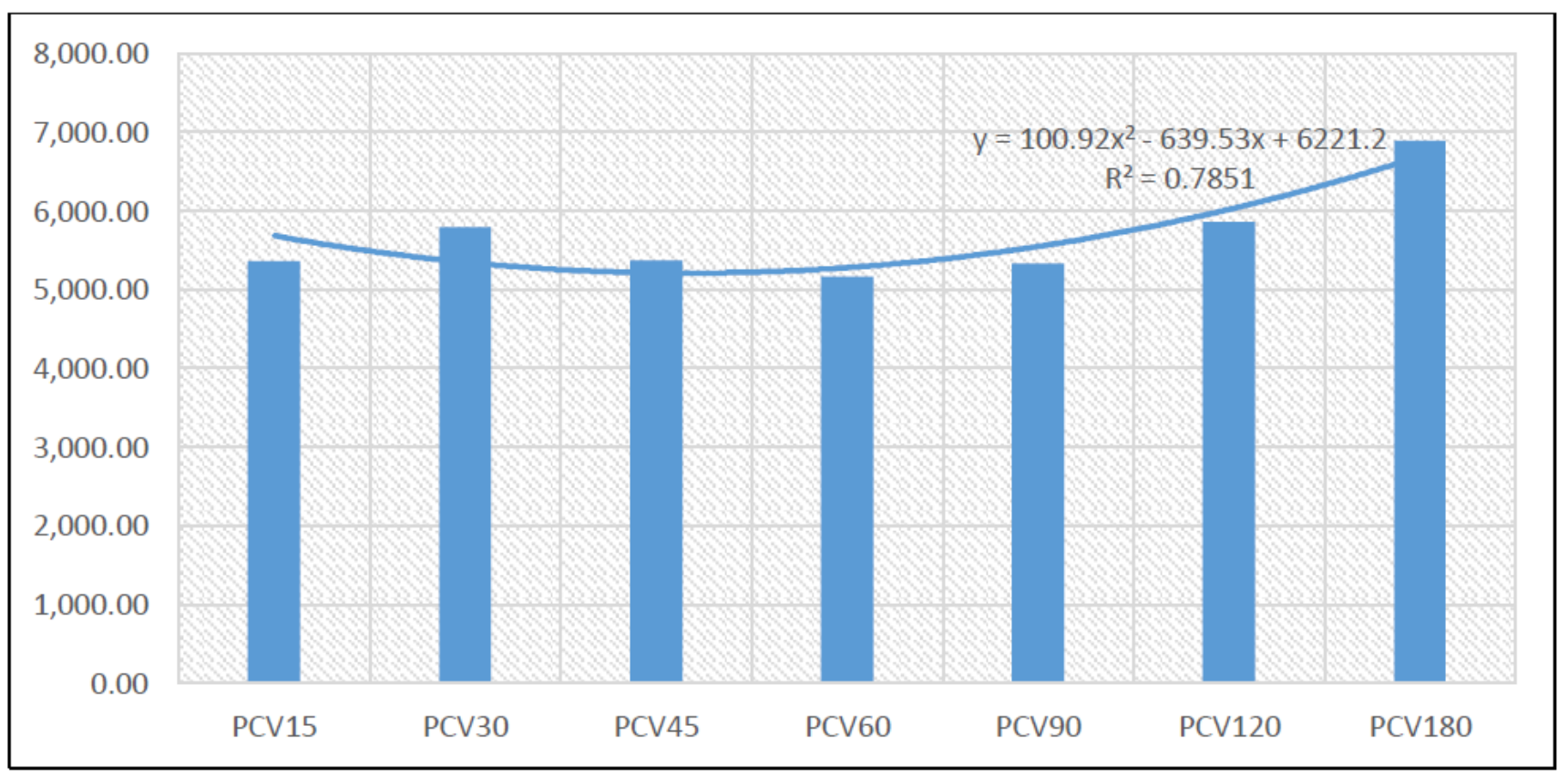

Figure 5

Distribution of PCV for Window Open 


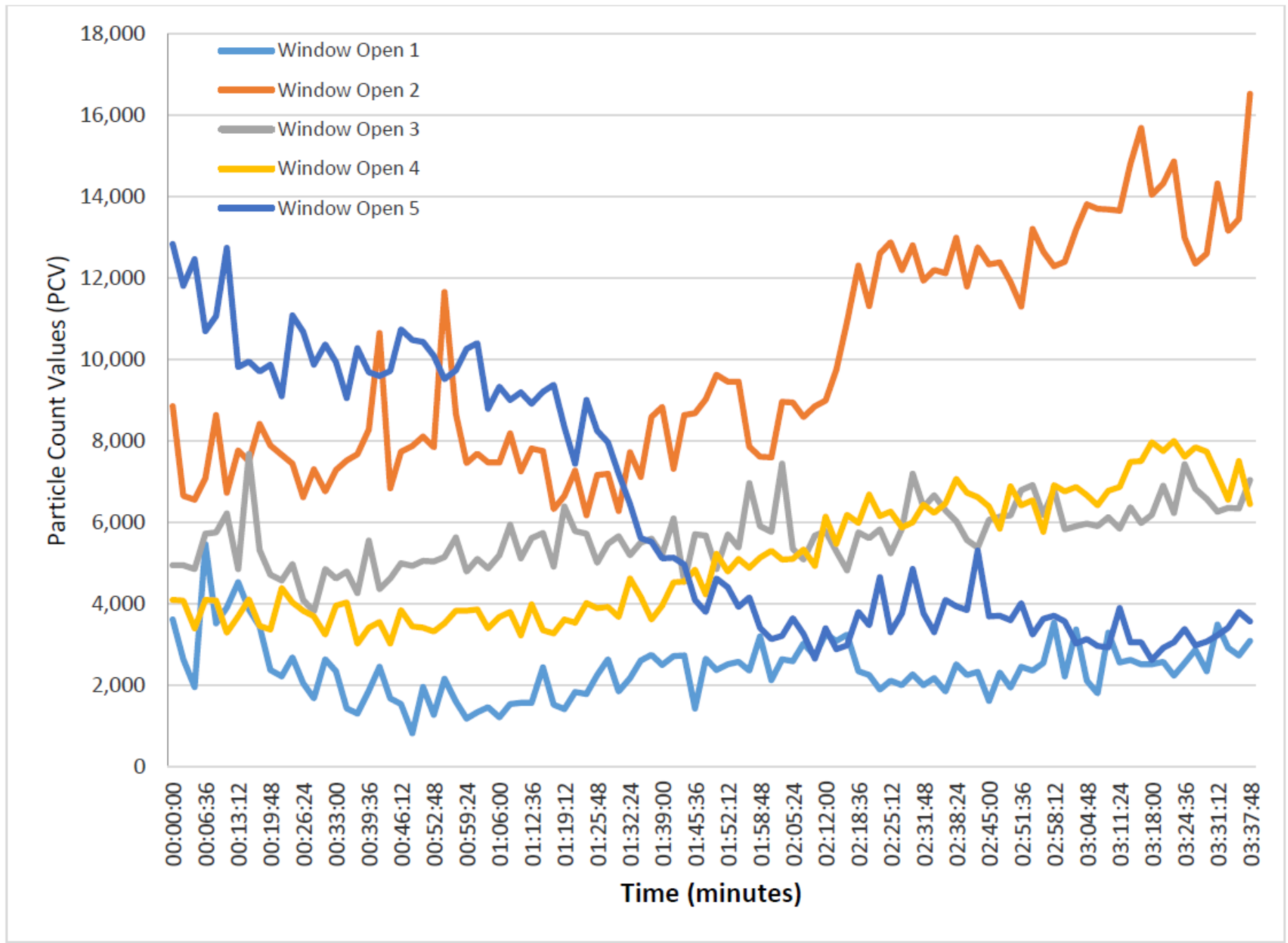

Figure 6

PCV over time for WO 


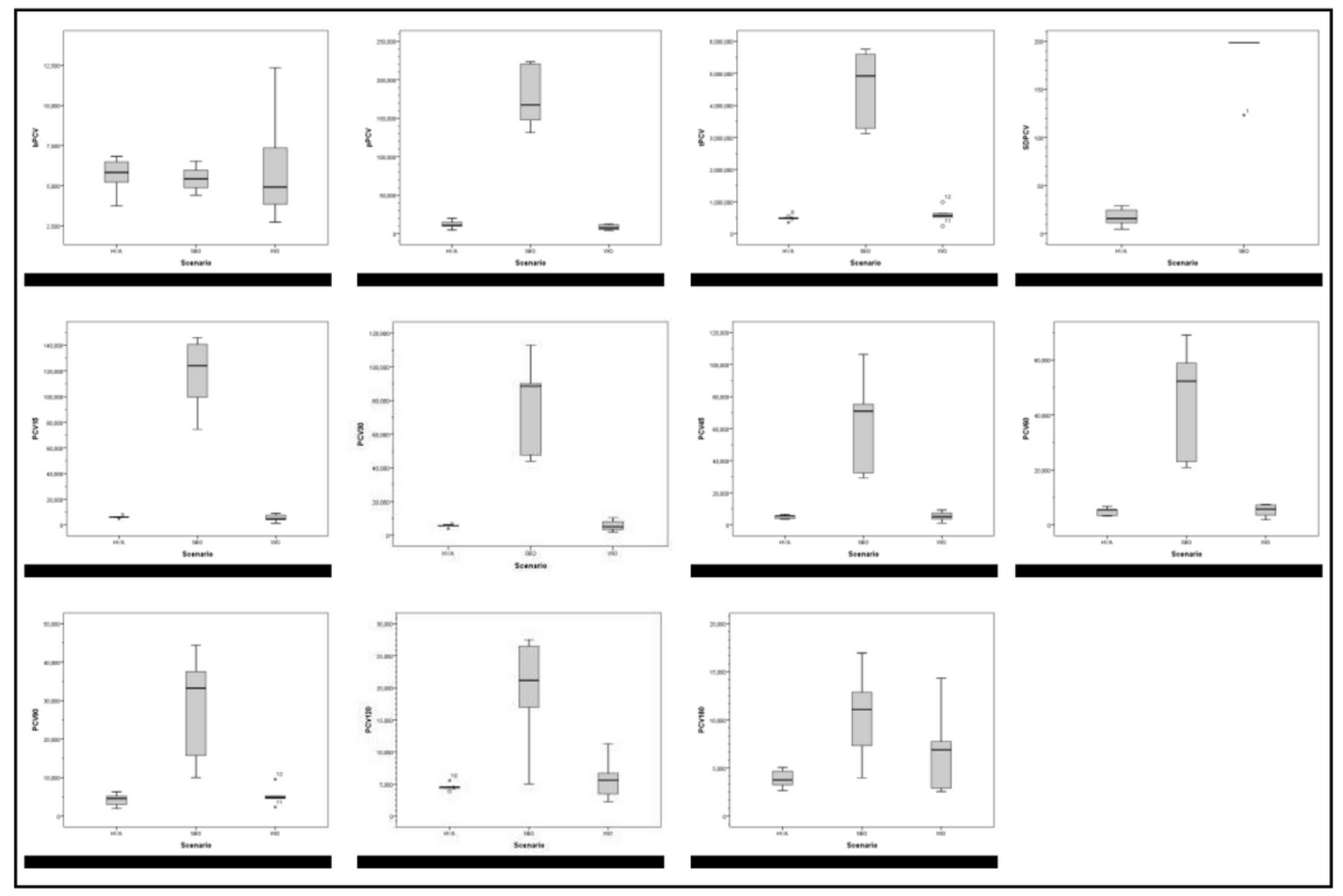

Figure 7

Box and whisker plots for bPCV, pPCV, tPCV, SDPCV, PCV15, PCV30, PCV45, PCV60, PCV90, PCV120 and PCV180. 